\title{
Tarefas matemáticas: interseção entre a avaliação e a comunicação
}

\author{
António Guerreiro ${ }^{a}$, Cristina Martins ${ }^{b}$ \\ aAntónio Guerreiro, Escola Superior de Educação e Comunicação, Universidade do Algarve, Faro, \\ Portugal, aguerrei@ualg.pt ${ }^{\text {b}}$ Centro de Investigação em Educação Básica, Instituto Politécnico de \\ Bragança, Bragança, Portugal, mcesm@ipb.pt
}

\section{Resumo}

As tarefas matemáticas deverão ser criadas com a principal intenção de gerar momentos significativos de aprendizagem para os alunos. Estes serão parceiros ativos no processo de ensino e de aprendizagem, cabendo ao professor selecionar as tarefas, orientar a comunicação, organizar o trabalho dos alunos e avaliar as aprendizagens. No estudo que temos vindo a desenvolver, a interseção entre a avaliação, a comunicação e as tarefas matemáticas surge como fundamental para responder à questão de investigação: Quais as relações existentes entre a avaliação $e$ a comunicação nas práticas dos professores de matemática? Nas fases concretizadas, foram analisadas as perceções e as práticas de quarto professores do $2 .^{\circ}$ ciclo do ensino básico, tendo sido possível compreender que as perceções se cruzam com as práticas. É evidente que a avaliação e a comunicação se relacionam através da utilização do diálogo, do questionamento e dos registos escritos, na interação e na partilha de ideias, em torno da realização de tarefas matemáticas em sala de aula. Dando seguimento à investigação em curso, neste artigo pretendemos avançar resultados da validação de uma tarefa matemática, construída com a intenção de cruzar os processos de avaliação e comunicação, numa turma de 5. ${ }^{\circ}$ ano. $O$ confronto entre as nossas expetativas e o desempenho dos alunos, constitui o ponto de partida para a reflexão conducente à validação da tarefa a desenvolver pelos professores participantes no estudo. Centrados no tópico "Capacidade de visualização e compreensão de propriedades de figuras geométricas e de sólidos geométricos”, a tarefa visa que o aluno seja capaz de explorar, analisar e interpretar situações em contextos variados, numa abordagem do espaço ao plano. Estes objetivos estão associados aos descritores do perfil dos alunos, no que respeita à utilização de linguagens verbais, não-verbais e simbólicas, à comunicação, ao raciocínio e resolução de problemas, ao pensamento crítico e sentido estético. 
Palavras-Chave: tarefas matemáticas, comunicação, avaliação, geometria.

\section{Introdução e apontamentos teóricos}

Analisar, investigar e reconhecer padrões nas práticas de ensino e de aprendizagem suscita o desenvolvimento da atividade de investigação em educação matemática, do conhecimento profissional e das práticas docentes em sala de aula. É nesta linha de ação que temos vindo a fortalecer um estudo sobre as relações entre a avaliação e a comunicação, tendo por propósito responder à seguinte questão de pesquisa: Que relação existe entre a avaliação e a comunicação nas aulas de matemática no $2 .^{\circ}$ ciclo do ensino básico? Neste artigo pretendemos dar conta dos resultados da validação de uma tarefa matemática, construída com a intenção de cruzar os processos de avaliação e comunicação, numa turma de $5 .^{\circ}$ ano.

Ressalvamos que os processos de avaliação e comunicação, bem como a consideração das tarefas a desenvolver em sala de aula são partes estruturantes do nosso trabalho. Adotámos a avaliação na sua dupla função de avaliar a aprendizagem e para a aprendizagem (Fernandes, 2015), aceitando uma dinâmica interativa entre aquilo que o aluno já aprendeu e aquilo que se perspetiva para as novas aprendizagens. Consideramos que o ato de avaliar é interno a qualquer processo de ensino e de aprendizagem, não o encarando como uma avaliação justificada no ato de classificar (Ulleberg \& Solen, 2018), mas como um real contributo para a aquisição e desenvolvimento de competências, integrando aptidões, conhecimentos e atitudes. A diversificação de ações de recolha, análise e registo da informação é fundamental e constitui a base para que as avaliações formativa e sumativa sejam rigorosas num contexto de interação social entre os alunos e entre estes e o professor (Santos, 2016).

A comunicação da aprendizagem decorre da narração, do conhecido dos alunos e do professor, enquanto que a comunicação para a aprendizagem aposta na aquisição de novas ideias matemáticas (Guerreiro \& Martins, 2018). Uma comunicação da aprendizagem centra-se no discurso oral e escrito dos alunos, sem valorizar a discussão e os diálogos em confronto entre os alunos. A comunicação para a aprendizagem não se restringe ao discurso dos alunos, mas aposta em evidenciar o seu pensamento, com o propósito de partilhar ideias e aprofundar o entendimento matemático dos alunos. Para "perceber que ideias matemáticas têm os alunos, como estão a pensar e que eventuais erros e dificuldades estão a sentir" (Guerreiro, Ferreira Tomás, Menezes \& Martinho, 2015, p. 287), os alunos precisam de "oportunidades para desenvolver pensamentos e ideias matemáticas em colaboração com 
os outros" (Ulleberg \& Solen, 2018, p. 18), numa atmosfera de sala de aula solidária e inclusiva.

A escolha das tarefas matemáticas a propor aos alunos é o aspeto central da planificação do processo de ensino e de aprendizagem. Os projetos, as investigações, os problemas e os exercícios são diferentes tipos de tarefas matemáticas (Ponte, 2005), exploradas na sala de aula, as quais promovem diferentes oportunidades de os alunos pensarem, numa variação entre a execução de procedimentos memorizados e a conceptualização das ideias e conceitos matemáticos (Stein \& Smith, 2009). O professor é responsável não só por conduzir a aula, mas também por escolher as tarefas, orientar a comunicação, organizar o trabalho dos alunos e avaliar as suas aprendizagens, num ambiente em que sejam valorizadas as ideias dos alunos.

\section{Apontamentos metodológicos e fases do estudo}

Adotamos um design de investigação interpretativo, com o intuito de interpretar, compreender e explicar significados, num contexto específico (Bogdan \& Biklen, 1994). O objetivo principal da investigação é estudar as relações entre a avaliação e a comunicação tendo em vista proporcionar significativas aprendizagens matemáticas dos alunos. Os participantes neste estudo, para além dos investigadores (autores deste artigo), são quatro professores do 2. ${ }^{\circ}$ ciclo do ensino básico (dois do distrito de Bragança e dois do distrito de Faro) que lecionam matemática neste nível de ensino. Esta investigação contempla as seguintes fases: (i) construção do referencial teórico, através da revisão da literatura; (ii) perceção dos professores, através da realização de entrevista semiestruturada; (iii) práticas profissionais dos professores, através da observação de aulas de matemática de uma mesma turma; (iv) experimentação na aula, através do desenvolvimento de tarefas matemáticas que relacionem conscientemente a avaliação e a comunicação; (v) reflexão, através da revisitação do referencial teórico e da indicação de práticas de sala de aula em que se verifique a existência de relações entre a avaliação e a comunicação na aula de matemática.

Até ao momento, o estudo contemplou um olhar sobre as principais ideias a propósito da avaliação e da comunicação, através da construção do referencial teórico e da averiguação das perceções e das práticas letivas dos professores (Martins \& Guerreiro, 2018). Na fase atual do estudo temos como principal objetivo desenvolver, em sala de aula, tarefas matemáticas que articulem intencionalmente a avaliação e a comunicação para a aprendizagem, perspetivando novas práticas profissionais dos professores de matemática. Com este propósito, optou-se por validar uma tarefa matemática com o objetivo de ratificar as diferentes questões, antes da sua implementação nas turmas dos professores deste estudo. 


\section{Validação da tarefa matemática: resultados}

A validação da tarefa matemática ocorreu numa turma do $5 .^{\circ}$ ano de uma escola do distrito de Bragança, com vinte e um alunos. Os professores desta turma, professora titular e professores estagiários, não integram os professores do projeto, disponibilizaram-se para testar a tarefa em contexto real, na presença do segundo autor como observador participante.

A capacidade de visualização e a compreensão de propriedades de figuras geométricas e de sólidos geométricos são conhecimentos matemáticos estruturantes no campo da geometria e medida. A planificação de um sólido geométrico requer o conhecimento das formas geométricas da sua superfície, as quais, no caso dos poliedros, são figuras geométricas planas. Uma mesma tarefa matemática poderá ter por objetivos a identificação de planificações de sólidos geométricos e a descrição de figuras no plano e no espaço, num contexto de resolução de problemas, em que se promove o raciocínio e a comunicação matemática.

A tarefa matemática assume uma vertente fechada com as características de problema (nomeadamente no respeitante à analise das características do sólido geométrico) e uma vertente aberta com as características de investigação (especificamente no respeitante à descoberta das planificações e da disposição das suas faces numa relação de duas cores), comportando diferentes etapas, as quais devem ser geridas pelo professor, mantendo uma dinâmica de apresentação, trabalho autónomo, discussão e síntese, sem quebras significativas, ao longo das distintas fases. Os alunos trabalharam em pares e tiveram por suporte fichas de trabalho e material didático (Polydron).

Com o apoio das questões apresentadas numa ficha de trabalho, o professor apresentou aos alunos a imagem de uma embalagem tetraedro (ver Figura 1), questionando-os: (i) Conhecem produtos embalados desta forma? Quais? (ii) Acham que se trata de um sólido geométrico? Porquê? e (iii) Conhecem o nome pelo qual é designado? O propósito destas questões foi trabalhar um conteúdo estritamente matemático a partir de um contexto não matemático. 


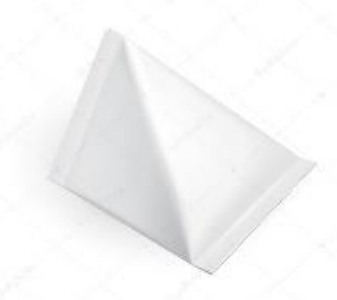

Fig. 1 Embalagem tetraedro

Fonte: recolha de imagens na internet

Após a discussão sobre o reconhecimento e as características da embalagem, o professor solicitou aos alunos que representassem as faces da embalagem. Com esta tarefa pretendeuse que o aluno reconheça um objeto tridimensional pela sua representação bidimensional e seja capaz de representar, a partir da gravura, as quatro faces triangulares do tetraedro.

Os alunos apresentaram significativas dificuldades em associarem a imagem, totalmente descaracterizada, a alguns produtos do quotidiano. Para ultrapassar esta dificuldade, o professor recorreu a embalagens concretas, no caso embalagens de chá, para ilustrar a existência de produtos embalados neste formato. Desta feita, o objetivo de avaliar se os alunos reconhecem sólidos geométricos em embalagens do quotidiano só foi concretizado a partir de embalagens concretas no formato de tetraedro. Atendendo aos dados, na implementação desta tarefa, o professor deverá utilizar embalagens concretas, para associar uma forma geométrica aos contextos sociais, e questionar os alunos sobre a existência de outras embalagens com o mesmo formato e com formatos distintos. Em relação à questão (ii), verificamos que os alunos associam os sólidos geométricos a objetos $3 \mathrm{D}$ e a poliedros, identificando as faces, arestas e vértices. No que concerne à questão (iii), os alunos designam como pirâmide triangular, a designação tetraedro não foi referida em nenhum momento. Estas respostas revelam um conhecimento geral sobre os sólidos geométricos, sem uma abordagem dos casos particulares dos sólidos platónicos. Uma deficiente abordagem dos poliedros regulares poderá ter como consequência a dificuldade em identificar o cubo como um caso particular dos prismas quadrangulares ou o tetraedro como um caso particular das pirâmides triangulares. Todos os pares de alunos representaram um ou quatro triângulos como as faces do tetraedro. Os pares que desenharam apenas um triângulo referiram, oralmente, que as restantes faces eram a repetição da representada. Com o objetivo de clarificar a questão, deverá ser reformulada para: Desenhem todas as faces da embalagem.

Num segundo momento, o professor solicitou aos alunos que descrevessem as características das faces do tetraedro: (i) Caracterizem cada uma das faces em relação à sua forma, (ii) Caracterizem cada uma das faces em relação à medida dos lados, e (iii) 
Caracterizem cada uma das faces em relação à medida dos ângulos. Pretendeu-se avaliar se os alunos eram capazes de identificar as faces triangulares e classificá-las quanto ao comprimento dos lados e quanto à amplitude dos ângulos, assumindo tratar-se de um tetraedro regular. Os alunos manifestaram alguma dificuldade em entender estas questões, revelando incompreensões no conceito genérico de medida para comprimento e para amplitude. No caso da forma, a maioria dos pares identificaram com triangular, mas dois pares associaram ao mesmo comprimento (dos lados), revelando uma incompreensão sobre a associação da forma com a superfície. No caso dos lados, a maioria dos pares identificou a figura com o triângulo equilátero. No caso dos ângulos, a maioria dos pares referiu triângulo acutângulo ou triângulo com ângulos agudos e iguais. Alguns pares trocaram os conceitos de classificação dos triângulos quanto ao comprimento dos lados e quanto à amplitude dos ângulos. Neste sentido, as questões deverão ser reformuladas com a designação concreta em cada caso, comprimento para os lados e amplitude para os ângulos.

Num terceiro momento, o professor solicitou aos alunos para identificarem quantas faces tem um tetraedro, quantos vértices e quantas arestas: (i) Quantas faces tem este sólido geométrico? (ii) E quantos vértices? (iii) E quantas arestas? Os alunos não revelaram qualquer dificuldade na resposta a estas três questões. Em relação à questão subsequente, Existirá alguma relação entre estes valores? alguns pares de alunos identificaram a relação de Euler, sendo que a mesma tinha sido abordada em aulas anteriores.

Em síntese, na primeira fase da tarefa, a que, pelas suas características, chamámos fase de resolução de problemas, as respostas dos alunos caracterizam o seu conhecimento e identificam algumas dificuldades relativas a conceitos matemáticos no campo da geometria e medida. Neste sentido, estas questões constituem uma possibilidade de avaliação da e para a aprendizagem com uma componente de comunicação matemática.

Na segunda fase da tarefa, a que chamámos fase de investigação matemática, o professor solicitou aos alunos que representassem as diferentes figuras que eram capazes de formar com quatro triângulos equiláteros iguais, recorrendo a material didático (peças triangulares do Polydron). Inicialmente, os alunos manifestaram dificuldade no entendimento da questão, alguns deles questionando se o que se pretendia era desenhar as planificações do sólido. Metade dos pares identificaram as planificações do tetraedro (ver figura 2) e dois pares identificaram a figura de quatro triângulos iguais que não é planificação (ver figura 3). Apenas um par identificou as três soluções. 

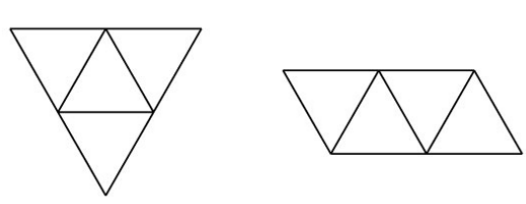

Fig. 2 Planificações do tetraedro

Fonte: construção dos autores

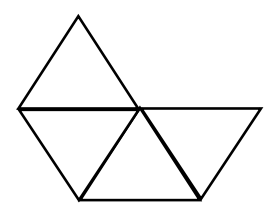

Fig. 3 Figura que não é planificação do tetraedro Fonte: construção dos autores

Os alunos manifestaram dificuldade nesta atividade de investigação matemática, revelando que estão muito condicionados pelas figuras que representam as planificações tradicionais dos sólidos geométricos. Ao serem questionados sobre quais das figuras eram e não eram planificações do tetraedro, os alunos identificaram as duas planificações que já tinham adiantado, na maioria, na questão anterior. Contudo, salientamos que questionados diretamente sobre a formulação da questão, consideraram que seria de mais fácil entendimento se lhes fosse pedido para desenharem as planificações do sólido. O propósito desta tarefa matemática foi levar os alunos a reconhecer que nem todos os arranjos de quatro triângulos são planificações do tetraedro.

Após esta etapa e seguindo o exposto na ficha de trabalho, o professor questionou os alunos sobre qual o número mínimo de cores necessário para colorir as faces de um tetraedro sendo que, cada face é de uma só cor e as faces que se unem na mesma aresta são de cores distintas. Esta descoberta foi, no geral, de fácil resolução para os alunos, nomeadamente porque a utilização das peças do Polydron veio dar-lhes a oportunidade de verificarem. Após a discussão sobre a inevitabilidade das quatro cores distintas, atendendo que cada face se liga com as restantes, os alunos compreenderam que cada face fica unida às restantes três.

No seguimento desta exploração, o professor solicitou aos alunos a construção de tetraedros de papel a duas cores. Distribuiu pelos grupos de alunos duas planificações, cada uma de sua cor, conforme apresentado na Figura 4. Sugeriu, então, aos alunos para construírem um tetraedro regular em papel, de duas cores distintas, a partir das duas planificações do tetraedro. O professor desafiou os alunos a construírem um único tetraedro com as duas tiras (planificações), sobrepostas (ver Figura 4).
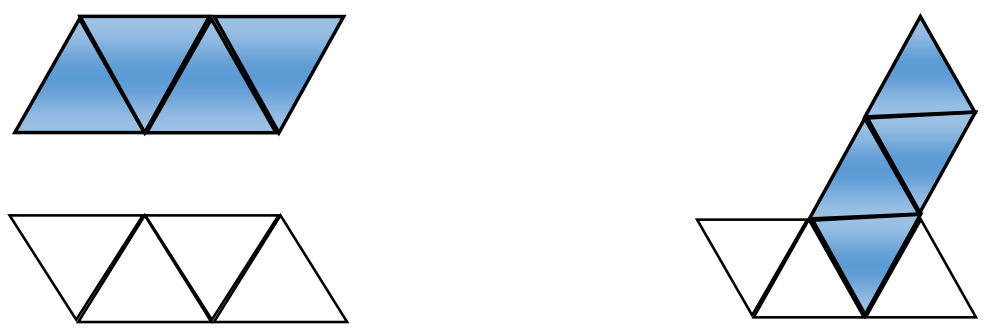

Figura 4: Planificações do tetraedro - duas cores (retirado de Gardner, 1992, p. 127). 
Os alunos insistiram, oralmente, que tinham sempre de sobrepor inicialmente duas faces para construir o tetraedro, não assumindo a possibilidade de entrelaçarem as fitas originando diferentes combinações de cores. Após a experimentação, o professor solicitou aos alunos que apresentassem um pequeno relatório com os diferentes sólidos geométricos, reforçando a ideia de se pronunciarem em relação à cor. Os relatórios limitaram-se a referir "concluímos que a cor da fase inicial é a que fica sobreposta na fase final". A simplicidade dos registos escritos revela que os alunos entendem a comunicação matemática escrita restrita ao registo das resoluções sem uma natureza argumentativa de construção do conhecimento matemático. Atendendo ao exposto, os alunos devem ser incentivados a apresentarem registos escritos mais detalhados com uma natureza justificativa das afirmações apresentadas.

\section{Nota final}

Dando seguimento à investigação em curso, os resultados divulgados neste artigo vieram dar ênfase à formulação das questões escritas, à (dificuldade da) interpretação das mesmas, ao diálogo estabelecido na sala de aula para averiguação dos conhecimentos matemáticos dos alunos, à escuta das suas opiniões e a importância desta para a compreensão dos seus raciocínios, dúvidas, erros e dificuldades, à importância das representações e registos escritos e à utilização de recursos materiais no processo de ensino-aprendizagemcomunicação-avaliação. Desta feita, e na prossecução do nosso objetivo, podemos constatar que a tarefa é adequada à avaliação e à comunicação das e para as aprendizagens. Salvaguardamos, pois, a necessidade de reformulação de algumas questões, conducente a uma melhor explicitação do pretendido. Reafirmamos que o confronto entre as nossas expetativas e o desempenho dos alunos, constituiu o ponto de partida para a reflexão conducente a esta validação desta tarefa, contudo a sua exploração em sala de aula suplantou o esperado. O próximo passo é, pois, o desenvolvimento da tarefa pelos professores participantes neste estudo, acreditando que a comunicação, as tarefas e a avaliação são três (ou mesmo os três) elementos fundamentais numa aula de matemática.

\section{Referências}

Bogdan, R., \& Biklen, S. (1994). Investigação qualitativa em educação. Porto: Porto editora.

Fernandes, D. (2015) Prefácio. In A. C. Neves \& A. L. Ferreira (2015), Avaliar é preciso? Guia prático de avaliação para professores e formadores (pp. 13-15). Lisboa: Guerra \& Paz.

Gardner, M. (1992). Rodas, Vida e outras diversões Matemáticas. Lisboa: Gradiva. 
Guerreiro, A., Ferreira, R. T., Menezes, L., \& Martinho, M. H. (2015). Comunicação na sala de aula: Perspetiva do ensino exploratório da matemática. Zetetiké, 23(44), 279-295.

Guerreiro, A., \& Martins, C. (2018). Avaliação e comunicação: da e para a aprendizagem. Educação \& Matemática, 149-150, 49-52.

Martins, C., \& Guerreiro, A. (2018). Avaliação e comunicação: convergência ou distanciamento entre perceções e práticas. XIV Congresso da Sociedade Portuguesa de Ciências da Educação. Coimbra, Portugal: Faculdade de Psicologia e de Ciências da Educação da Universidade de Coimbra.

Ponte, J. P. (2005). Gestão curricular em Matemática. In GTI (Ed.), O professor e o desenvolvimento curricular (pp. 11-34). Lisboa: APM.

Santos, L. (2016). A articulação entre a avaliação somativa e a formativa, na prática pedagógica: uma impossibilidade ou um desafio? Ensaio, 24(92), 637-669.

Stein, M., \& Smith, M. (2009). Tarefas matemáticas como quadro para a reflexão: Da investigação à prática. Educação \& Matemática, 105, 22-28.

Ulleberg, I., \& Solen, I. (2018). Which questions should be asked in classroom talk in mathematics? Presentation and discussion of a questioning model. Acta Didactica Norge. 12(1), 1-21. 